\title{
Vinheta televisiva: usos e funções
}

Jaqueline Esther Schiavoni ${ }^{1}$ ECA/USP

1. Doutoranda no Programa de Meios e Processos Audiovisuais da Escola de Comunicação e Artes da Universidade de São Paulo. 


\section{Resumo}

O objetivo deste artigo é pensar os usos e funções da vinheta na televisão. Ela acompanhou as mudanças sofridas pela própria TV brasileira e, em decorrência disso, deixou de ser apenas um suporte de divulgação da programação e passou a desempenhar um importante papel no estabelecimento do que divulga, seja a emissora (ou suas afiliadas), seja a programação, e na divisão do tempo televisivo.

\section{Palavras-chave}

vinheta, televisão brasileira, identificação, autorreferencialidade, serialidade

\section{Abstract}

The objective of this article is to think the uses and functions of the vignette at television. It accompanied the changes of Brazilian television, and, as a result, it's not anymore just a support for programming dissemination. It plays an important role in establishing what it discloses, no matter they are the TV company itself (or its affiliates) or the programming, and in the division of television time.

\section{Key-words}

vignette, television, identification, self-referential, seriality 
Vinheta significa "pequena vinha”. Apesar do estranhamento que a definição possa causar, ela traduz bem a origem do termo, que remonta às iluminuras contidas nas escrituras sagradas da Idade Média. Como se sabe, a videira possui grande valor simbólico nesses textos e, por vezes, foi utilizada em forma de desenho para tornar mais acessíveis algumas das passagens bíblicas. A ideia deste artigo é apresentar o modo como a vinheta é utilizada na mídia televisiva para, por fim, comparar suas características com as das vinhetas originais do meio tipográfico.

Um retorno ao início das transmissões televisivas no país trará à mente que as primeiras vinhetas utilizadas eram, na verdade, imagens paradas, produzidas à mão sobre uma cartolina. O desenho e o nome da atração televisiva eram filmados e persistiam no ar pelo período de 10 a 40 minutos, enquanto eram feitos os ajustes de produção para o próximo programa entrar no ar.

Esse primeiro momento evidencia que a vinheta na televisão seria marcada por um viés publicitário, servindo de suporte para a apresentação de marcas e produtos. Evidentemente, muitos outros aspectos ligados à comunicação acabavam sendo embutidos nessa proposta. Anunciar o nome da emissora ou dos programas, e os horários de veiculação da programação, era uma forma colocar o telespectador a par do que aconteceria na grade, mas, ao mesmo tempo, uma forma de segurá-lo por mais tempo diante do aparelho. O resultado desse processo é o que se conhece hoje por autorreferencialidade, um dos elementos formadores da estética da televisão, do qual se falará mais adiante. 
Aos poucos, houve a profissionalização da TV, e esquemas técnicos foram sendo desenvolvidos para que os cartazes pudessem ser trocados com maior rapidez — dando a impressão de imagem em movimento. O primeiro grande salto de qualidade na produção, entretanto, se deu mesmo com o surgimento do videotape, que passou a ser o instrumento de trabalho dos vinhetistas. As imagens podiam ser trabalhadas, sobrepostas, criando quadros espetaculares, como, de fato, foi feito em muitas vinhetas da época. $\mathrm{O}$ avanço, evidentemente, não se limitou a esse produto. Com o recurso do videotape, a linguagem televisiva, de modo geral, começava a se configurar. Foi nesse momento que se tornou possível, por exemplo, planejar uma programação tanto vertical (sequência de conteúdos no decorrer do dia) quanto horizontalmente (sequência de conteúdos no decorrer da semana, mês etc.).

\section{A linguagem atual da vinheta na televisão}

Embora a linguagem analógica e o recurso do videotape tenham sido utilizados durante décadas na televisão, as vinhetas atuais, em sua maioria, não são mais feitas dessa forma. Hoje, a ferramenta de produção que se destaca é a computação gráfica. E é essa a linguagem responsável pelo segundo grande salto de qualidade na produção da vinheta televisiva. O motivo é simples: as imagens produzidas pela computação gráfica são de natureza sintética, fruto de elaborações digitais regidas por procedimentos lógico-matemáticos.

O termo sintético muitas vezes traduz a ideia de síntese, de algo resumido. De certo, toda representação implica uma perda em relação ao objeto representado, conservando - tal como um resumo - apenas os traços essenciais para sua existência ou seu reconhecimento. Mas esse não é o sentido que se traz na definição esboçada anteriormente. Nela, o termo sintético significa que as imagens são captadas e reduzidas a um código binário - facilitando a compressão e o transporte da informação - , para posteriormente serem revertidas em imagem.

Deixa-se, portanto, a automatização analógica e passa-se à automatização numérica da imagem. Se, no primeiro caso, chamado de 'morfogênese por projeção', era necessária a presença de um objeto real preexistente à imagem; no segundo, se existe alguma coisa que preexiste ao pixel é o próprio programa, isto é, linguagem e números, e não mais o real. 
A realidade que a imagem numérica dá a ver é uma outra realidade: uma realidade sintetizada, artificial, sem substrato material além da nuvem eletrônica de bilhões de microimpulsos que percorrem os circuitos eletrônicos do computador, uma realidade cuja única realidade é virtual. Nesse sentido, pode-se dizer que a imagem-matriz digital não apresenta mais nenhuma aderência ao real: libera-se dele. Faz entrar a lógica da figuração na era da simulação (Couchot, 1993, p. 42).

A automatização numérica coloca, assim, um aspecto importante: a manipulação. Na medida em que a busca pelo menor elemento constituinte da imagem foi superada pelo computador, o domínio total sobre o pixel abriu possibilidades várias de interferência na imagem pelo homem. Com isso, a aplicação das TICs (tecnologias da informação e da comunicação) marca não apenas uma revolução das técnicas figurativas de representação, mas, em consequência disso, um novo modo de sentir e perceber do homem, sobretudo porque o computador não conhece as limitações técnicas que restringiam as imagens fotográficas, cinematográficas e televisuais. E mais, tudo o que era inconcebível ou desconhecido no mundo real agora passa a ser possível no mundo virtual:

Se o computador trabalha basicamente com cálculos matemáticos e leis puras da física, ele pode trazer à luz imagens que nunca foram antes captadas por um olho humano, sejam elas 'realistas' (no sentido de verossímeis num universo de possibilidades), sejam elas assumidamente abstratas. Para ele, o mundo humano conhecido $e$ fisicamente experimentado não é senão uma das possibilidades de atualização do universo formal das matemáticas e das leis físicas do universo (Machado, 2001, p. 131).

Trata-se, de fato, de uma hiper-realidade criada pelo computador. Além dos aspectos relacionados ao poder de criação, comentados anteriormente, a possibilidade de manipulação total sobre a imagem a partir do domínio do pixel permitiu também intensificar o real em suas cores, formas e propriedades, a ponto de produzir uma "imagem-cópia”, mais interessante que a realidade.

E isso explica aquilo que é exatamente a essência da pós-modernidade: a preferência pela imagem ao objeto, pelo simulacro ao 
real. O fato é que os meios tecnológicos de comunicação, que se colocam entre o homem e o mundo, não mais informam sobre o mundo, antes, o refazem à sua maneira, hiper-realizam o mundo, transformando-o num verdadeiro espetáculo.

Em consequência, "somos levados a exagerar nossas expectativas e modelamos nossa sensibilidade por imagens sedutoras" (Santos, 1994, p. 13). É o caso, por exemplo, da dona de casa que termina o dia frustrada quando seu bolo não corresponde à imagem que ela vê na embalagem do produto que adquiriu. O fato é que não haverá um final feliz. E a pobre dona de casa não deve se culpar pelo resultado sempre inferior, simplesmente porque a imagem da propaganda que a seduziu não corresponde ao real e jamais existiu. É, em vez disso, uma simulação que supervaloriza as características dos objetos em questão e, por essa razão, o bolo da caixinha será sempre mais convidativo que o bolo real, feito em casa.

Se, na Idade Média, a vinheta tinha por objetivo chamar a atenção para o conteúdo do texto escrito que adornava, funcionando como uma espécie de deleite visual, não há dúvida de que, com a computação gráfica, a função de adorno da vinheta atingiu condições de expressão fantásticas, envolvendo o telespectador e firmando com ele contratos indispensáveis para a comunicação.

\section{Usos e funções da vinheta televisiva}

Pode-se dizer que a utilização da vinheta como suporte de divulgação dos nomes do programa e da emissora persiste ainda nos dias de hoje, bem como o uso de desenhos ilustrativos, que referenciavam os programas nos primórdios da TV - só que, como visto anteriormente, de modo bem mais incrementado. O tempo que permanecem no ar não é mais um período entre 10 e 40 minutos, mas algo entre 5 e 10 segundos, de modo geral.

As mudanças que podem ser sentidas nas vinhetas são, na verdade, reflexos de um processo de desenvolvimento da própria televisão. E a vinheta, em decorrência disso, deixou de ser apenas um suporte de divulgação e passou a desempenhar um importante papel no estabelecimento das marcas que divulga, como uma espécie de embalagem que, por seus atributos e estratégias, é capaz de seduzir e conquistar o consumidor - o telespectador, nesse caso. 
Mas e quanto à televisão de modo geral? Que papéis desempenham as vinhetas? Apontou-se que um dos aspectos constituintes da estética da televisão é a autorreferencialidade, que diz respeito ao seu caráter metalinguístico. E isso por um motivo bastante simples: quem não anuncia não vende e dificilmente se consolida na memória do público. A tabela que segue evidencia melhor a característica da autorreferencialidade, apontando suas formas de aparição e com que frequência ocorre na TV. Identificar tais aspectos é o primeiro passo para compreender as contribuições que a vinheta pode oferecer ao meio televisivo.

O primeiro aspecto que deve ser mencionado sobre a tabela é que ela traz dados referentes às quatro principais emissoras comerciais do país, em termos de audiência e faturamento - Globo, Record, SBT (Sistema Brasileiro de Televisão) e Bandeirantes - e também à TV Cultura, televisão pública do Estado de São Paulo. A ideia é mostrar que tanto num caso como noutro, quer dizer, em televisões com caráter mais ou menos comercial, a autorreferencialidade está igualmente presente e segue as mesmas estratégias de aparição.

Outro ponto é que em cada emissora há dados de diferentes tipos de programa. Assim, foram analisados os intervalos comerciais de telejornais, novelas, revistas eletrônicas, reality shows e programas femininos, musicais, esportivos e de entrevista. Ou seja, formas variadas, que buscam demonstrar que a autorreferencialidade é uma característica da televisão e aparece em toda a grade, e não apenas em certos segmentos da programação.

E aparece como? Os programas, de modo geral, são interrompidos por três blocos comerciais. Desse modo, tem-se uma estrutura como essa: Programa + Intervalo + Programa + Intervalo + Programa + Intervalo + Programa. Por isso, na tabela, discriminou-se a estrutura de cada um desses intervalos, chamados intervalos de programa. No entanto, quando o último trecho do programa chega a seu fim, a passagem para a próxima atração não é direta. Há sempre, entre um programa e outro (um telejornal e uma novela, por exemplo), a exibição de um intervalo, que é menor, mais rápido, mas ainda assim um intervalo. Essa aparição, chamada de intervalo entre programas, leva a sigla "IEP" na tabela e também foi analisada. Mas como se estruturam, em geral, esses intervalos de programa e entre programas? 
Tabela 1. Autorreferencialidade: aparições e frequência na TV brasileira

\section{Rede Globo de Televisão}

\begin{tabular}{|c|c|c|c|}
\hline & Telejornal & Novela & Revista eletrônica \\
\hline $1^{\circ}$ bloco & $\mathrm{P}_{1}$ RCCCRIAAAACR $2 \mathrm{P}$ & $\mathrm{P}_{1}$ RCCCCRGCCCR $2 \mathrm{P}$ & ${ }_{1} \mathrm{P}_{2} \mathrm{RICCRCCCR} 2 \mathrm{P}$ \\
\hline $2^{\circ}$ bloco & $\mathrm{P}_{2} \mathrm{RCCCRICCR}_{2} \mathrm{P}$ & $\mathrm{P}_{2} \mathrm{RCCRCRCCCIR}_{2} \mathrm{P}$ & $\mathrm{P}_{2} \mathrm{RCCIRCICCRA} \mathrm{P}_{3}$ \\
\hline $3^{\circ}$ bloco & $\underline{\mathrm{P}_{2} \mathrm{RCRCIAAAAACCR}} 2 \mathrm{P}$ & $\mathrm{P}_{2} \mathrm{RCCRRCGRA}_{2} \mathrm{P}_{3}$ & \\
\hline IEP & RP1 & RARP & RCP \\
\hline
\end{tabular}

\section{REDE RECORD DE TELEVISÃO}

\begin{tabular}{|c|c|c|c|}
\hline & Telejornal & Novela & Reality show \\
\hline $1^{\circ}$ bloco & $\mathrm{P}_{1} \mathrm{P}_{2} \mathrm{CCCRAAAARCCR} 2 \mathrm{P}$ & $\mathrm{P}_{1} \mathrm{RCCCCCCRAACCCCCI} 2 \mathrm{P}$ & ${ }_{1} \mathrm{P}_{2}$ RCCCRRCCCCIR $2 \mathrm{P}$ \\
\hline $2^{\mathrm{o}}$ bloco & $\mathrm{P}_{2} \mathrm{CIAAAAACCCC} 2 \mathrm{P}$ & $\mathrm{P}_{2} \mathrm{RCCCCCCCC}_{2} \mathrm{P}$ & $\mathrm{P}_{2} \mathrm{RCRCRCCCCRAAAAAAA} 2 \mathrm{P}$ \\
\hline $3^{\circ}$ bloco & $\mathrm{P}_{2} \mathrm{CCRAAAARCI}_{2} \mathrm{P}_{3}$ & $\mathrm{PRCRAACCCCCC}_{2} \mathrm{P}_{3}$ & \\
\hline IEP & RICRP & RIP & PRP \\
\hline
\end{tabular}

\section{SISTEMA BRASILEIRO DE TELEVISÃO}

\begin{tabular}{|c|c|c|c|}
\hline & Prog. entrevista & Telejornal & Prog. musical \\
\hline $1^{\circ}$ bloco & $\mathrm{P}_{1} \mathrm{P}_{2} \mathrm{RACCCCCCCC} 2 \mathrm{P}$ & $\mathrm{P}_{1} \mathrm{P}_{2} \mathrm{CCCCC}_{2} \mathrm{P}$ & ${ }_{1} \mathrm{PRCCCCCCCC}_{2} \mathrm{P}$ \\
\hline $2^{\circ}$ bloco & $\mathrm{P}_{2} \mathrm{RAAACCCCCCCAA_{2 }} \mathrm{P}$ & $\mathrm{P}_{2} \mathrm{CGCI}_{2} \mathrm{P}$ & $\mathrm{P}_{2} \mathrm{CCGGCCCCCI}_{2} \mathrm{P}$ \\
\hline $3^{\circ}$ bloco & $\mathrm{P}_{2} \mathrm{RACCCCG}_{2} \mathrm{P}_{3}$ & $\underline{\mathrm{P}_{2} \mathrm{GCGCG}_{2} \mathrm{P}}$ & $\mathrm{P}_{2} \mathrm{RCGCGCCCCCC}_{2} \mathrm{P}_{3}$ \\
\hline IEP & $\mathrm{R}_{4} \mathrm{P}$ & RAAIR & RAAAAARIRAA \\
\hline
\end{tabular}

\section{REDE BANDEIRANTES DE TELEVISÃO}

\begin{tabular}{|c|c|c|c|}
\hline & Prog. feminino & Prog. de esporte & Telejornal \\
\hline $1^{\circ}$ bloco & ${ }_{1} \mathrm{P}_{2} \mathrm{RCCCRCCCCR} 2 \mathrm{P}$ & ${ }_{1} \mathrm{P}_{2}$ CCICRCIRACCCRRAA $2 \mathrm{P}$ & ${ }_{1} \mathrm{PI}_{4} \mathrm{CRAAA}_{2} \mathrm{P}$ \\
\hline $2^{\circ}$ bloco & $\mathrm{P}_{2} \mathrm{RCCCCCCCR}_{2} \mathrm{P}$ & $\mathrm{P}_{2} \mathrm{RCCCCCCRRA}_{2} \mathrm{P}$ & $\mathrm{P}_{2} \mathrm{RACCCCCRIAA}_{4} \mathrm{RA}_{2} \mathrm{P}$ \\
\hline $3^{\circ}$ bloco & $\mathrm{P}_{2} \mathrm{RCCCCRR}_{4} \mathrm{CCCR}_{2} \mathrm{P}$ & $\mathrm{P}_{2} \mathrm{RCCCCCCCIRAAA}_{2} \mathrm{P}_{3}$ & $\mathrm{P}_{2} \mathrm{RACCCIR}_{2} \mathrm{P}$ \\
\hline IEP & $\mathrm{P}_{34} \mathrm{P}$ & RAAAIIRAA & $\mathrm{P}_{3} \mathrm{RAAAI}_{4} \mathrm{RAP}$ \\
\hline
\end{tabular}

\section{FUNDAÇÃO PADRE ANCHIETA}

\begin{tabular}{|c|c|c|c|}
\hline & Telejornal & Revista eletrônica & Prog. entrevista \\
\hline $1^{\circ}$ bloco & $\mathrm{P}_{1} \mathrm{P}_{2} \mathrm{RAAARCCRCR} 42 \mathrm{P}$ & ${ }_{1} \mathrm{P}_{2} \mathrm{RAACCCCCR}_{42} \mathrm{P}$ & ${ }_{1} \mathrm{P}_{2} \mathrm{RAACCCIR}_{42} \mathrm{P}$ \\
\hline $2^{\circ}$ bloco & $\mathrm{P}_{2} \mathrm{RACCRCCR}_{42} \mathrm{P}$ & $\mathrm{P}_{2} \mathrm{RAACCCCCR}_{4} \mathrm{P}$ & $\mathrm{P}_{2} \mathrm{RACRCIR}_{42} \mathrm{P}$ \\
\hline $3^{\circ}$ bloco & $\underline{\mathrm{P}_{2} \mathrm{RIRCR}_{4} \mathrm{P}}$ & $\mathrm{P}_{2} \mathrm{CCCCCCCIARAA}_{2} \mathrm{P}_{3}$ & $\mathrm{P}_{2} \mathrm{RCRCIR}_{42} \mathrm{P}_{3}$ \\
\hline IEP & ${ }_{4} \mathrm{RAARRAAAACR}_{4}$ & ${ }_{4}$ RAAARCCRAA & ${ }_{4} \mathrm{RAAARR}_{4}$ \\
\hline
\end{tabular}


Evidentemente, há comerciais de veiculação nacional e de âmbito local. Para este trabalho, no entanto, a distinção entre essas categorias não é algo importante. Tão pouco é relevante o tipo de produto anunciado. Não importa se se trata de produto de higiene ou limpeza de ou venda de veículos, brinquedos, roupa ou alimento. $\mathrm{O}$ que vale é que as marcas, produtos e os serviços anunciados não possuem qualquer ligação com a emissora. Esse tipo de comercial leva na tabela a sigla "C".

Como as empresas de televisão são sustentadas em maior ou menor grau pelos anunciantes, o primeiro pensamento que vem à mente é que esse tipo de comercial é o que aparece em maior quantidade nos intervalos. Certo? Errado. De modo geral, a quantidade de vezes que esses comerciais aparecem corresponde a menos da metade das inserções totais. Na TV Cultura, em que essa dinâmica é mais evidente, eles ocupam apenas $18 \%$ do intervalo. Nas outras emissoras, mais: na Band, são 40\%; na Globo, 42\%,; no SBT, 53\%; e, na Record, 61\%.

Vale dizer que essa porcentagem foi feita a partir dos blocos sem comerciais de apoio à programação. Por quê? Porque esses comerciais constituem um tipo híbrido. Ao mesmo tempo em que destacam um serviço, um produto ou uma marca independente da emissora, o que lhes colocaria na nomenclatura "C" da tabela, sua aparição está atrelada à programação televisiva, e isso termina por lhes conferir uma aparição mais curta e rápida e, geralmente, vinculada à linguagem (muitas vezes musical) do programa que apoiam. Por esses motivos, ganham na tabela a nomenclatura "A" e, por rigor de análise, os blocos em que aparecem não foram utilizados nessa estimativa de valores.

A pergunta que surge, então, é: se, em geral, os comerciais independentes, do tipo "C" na tabela, ocupam menos da metade dos intervalos, que tipo de aparição compõe o restante do espaço disponível? Aqui, se começa a vislumbrar o caráter autorreferencial da televisão.

Além dos comerciais independentes e dos comerciais de apoio, os intervalos são compostos por três outros tipos: 1) comerciais de produtos do grupo; 2) comerciais institucionais; e 3) comerciais autorreferenciais. Diferentemente dos casos anteriores, em todos esses há uma relação de dependência dos serviços, dos produtos ou das marcas anunciados com a própria emissora.

O primeiro tipo citado diz respeito a comerciais que anunciam produtos do grupo responsável pela rede de televisão. Eles levam na tabela a nomenclatura "G". O caso mais conhecido, talvez, seja o 
do Grupo Silvio Santos. Sabe-se que, além do canal de TV, o grupo possui outras empresas, como a Jequiti (cosméticos) ou a Liderança Capitalização, responsável pela Tele Sena. E elas, frequentemente, são anunciadas nos intervalos. Mas pode-se ir além. Há vezes em que certos produtos ou serviços terminam por levar, diretamente, a marca da emissora. É o que acontece com alguns brinquedos, como o Jogo do Milhão, criado em decorrência do sucesso da atração televisiva. Embora os comerciais de produtos do grupo sejam mais evidentes no SBT, acontecem também em outras emissoras. A Rede Globo anuncia em seus intervalos o Canal Futura, que é uma televisão cujos mantenedores são organizações privadas, e o Globo Mídia Center (que disponibiliza conteúdos na internet). Também nesses casos acaba havendo a aparição da marca da emissora.

O segundo tipo são comerciais financiados pela emissora ou por afiliada, apesar de o objeto da mensagem não pertencer à emissora ou não ter uma relação de dependência com ela. É comum, por exemplo, o patrocínio de mensagens comemorativas de aniversário de cidades, de Dias das Mães, dos Pais, dos Namorados, e assim por diante. Por vezes, emissoras patrocinam também campanhas de cidadania e saúde. O fato é que todas essas produções acabam levando a assinatura do canal. Na tabela, esses comerciais assumem a nomenclatura "I", de institucional.

Por fim, os comerciais autorreferenciais são aqueles que fazem referência direta à grade de programação, indicando o horário e o conteúdo das atrações televisivas. São comerciais que avisam sobre a trama da novela, os destaques do esporte ou as notícias do jornal. Enfim, mensagens que colocam o telespectador a par de tudo o que irá acontecer no dia, na semana ou naquele mês na emissora. Na tabela, visto que referenciam os programas, levam a nomenclatura "R".

A aparição constante das indicações "G", "I" e "R" no quadro evidencia que a autorreferência, de um modo ou de outro, faz parte da estética da televisão. Isso porque, como visto anteriormente, os comerciais de grupo, os institucionais e os autorreferenciais terminam sempre por levar a marca da emissora, que se promove ou promove seus produtos. Mas ainda há mais.

O quadro sobre a metalinguagem na televisão traz também a numeração 1, 2, 3 e 4. Essa sequência indica os diferentes tipos de vinheta que aparecem na programação. São elas: 1) vinhetas de abertura; 2) vinhetas de passagem; 3) vinhetas de encerramento e 4) 
vinhetas institucionais. O que significam e como são usadas?

As vinhetas de abertura são videografismos que marcam o início dos programas, apresentando-os. São muitas vezes narrativas descritivas ou mensagens que buscam efetivar contratos com o telespectador. Em todos os casos, há sempre a apresentação do nome da atração. Já as vinhetas de passagem, como o nome indica, fazem a transição entre a veiculação do programa e os comerciais. Por isso, estão presentes em cada início e fim de intervalo. Esse tipo de vinheta é sempre um recorte das de abertura, o que lhes imprime um caráter abreviado e menor tempo de exibição. As vinhetas de encerramento, por sua vez, marcam o término dos programas e podem apresentar os créditos finais. Mas é comum a emissora não fazer uso delas e finalizar as atrações com as imagens do programa (estúdio, auditório, sala de redação etc.).

Enquanto as vinhetas de abertura, passagem e encerramento giram em torno de produtos televisivos, a vinheta institucional traz a marca da emissora ou de alguma afiliada. Assim como as outras, podem ser visuais, sonoras ou audiovisuais. E cada uma dessas linguagens pode ser usada a serviço da autorreferencialidade. As imagens, por exemplo, podem fazer referência à emissora por meio de logotipos ou logomarcas; ruídos e músicas podem ser taticamente utilizados como elementos de identidade e, por sua persistência no ar, serem apontados pelo telespectador como pertencentes a um canal específico. Por último, jingles e spots usualmente referenciam as emissoras pelo texto verbal, citando-as diretamente ou tratando de suas formas de atuação.

É importante dizer que as vinhetas - tanto as que giram em torno de produtos como as que giram em torno da emissora - não se limitam a essas formas de aparição "pura” esboçadas nos parágrafos anteriores. Elas, via de regra, estão presentes também no interior dos comerciais institucionais e autorreferenciais, sob a forma de uma aparição breve, como uma assinatura ou um cartaz.

O interessante é que esses comerciais e essas vinhetas não aparecem de modo aleatório nos intervalos, mas seguem uma sistemática de apresentação que termina por servir de 'aviso' ao telespectador. Como assim? Acontece que os blocos comerciais, de modo geral, sempre terminam com a apresentação de um comercial referencial, seguido de uma vinheta de passagem do programa em curso. E logo depois vem a atração mencionada.

Essa estratégia é levada ao ar repetidas vezes todos os dias, e o hábito faz que o telespectador pressinta (mesmo sem ter consciência 
da estratégia) que o intervalo terminará em breve. Assim, pode fazer seus últimos ajustes e voltar ao ecrã sem perder parte da atração televisiva que deseja ver.

Quando o comercial referencial que antecede a entrada do programa é de apoio à programação, esse "sinal de aviso" ao telespectador fica ainda mais evidente. Além de ter um texto mais curto, a locução desse tipo de comercial autorreferencial é mais rápida. Por isso, a sequência de três ou quatro deles, como é comum acontecer, imprime um ritmo bem mais dinâmico para o final do break. A percepção do telespectador, então, capta com mais facilidade a "mensagem de finalização" do intervalo.

Essa estratégia para a "entrada" da programação é usada também para a "saída" dela. Aliás, foi para tornar mais suave a transição entre as atrações e os comerciais que se criou na Rede Globo, por exemplo, a vinheta do "plim plim", no início da década de 70. Ela interrompia a exibição de filmes e seriados, pedindo licença para uma palavrinha dos patrocinadores. A ideia, que veio do diretor José Bonifácio de Oliveira Sobrinho, o Boni, contemplava também o retorno do telespectador à tela. Ele desejava algo que pudesse ser ouvido a quadras de distância e que fizesse a família voltar rapidinho para a frente da TV. O artista Borjalo então desenhou o logotipo da vinheta e criou o ruído, que inicialmente era um "bip bip", que representava a abertura e o fechamento do diafragma de uma máquina fotográfica. Com o tempo, a vinheta foi ganhando novas roupagens, especialmente com a entrada do designer Hans Donner na emissora, que alterou a logomarca da rede e deu ao "bip bip" um som mais estridente, culminando no "plim plim" que se conhece hoje.

E o uso da vinheta não termina por aí. No desenvolvimento de alguns programas, tais como as revistas eletrônicas, esses videografismos têm papel fundamental. Eles são os responsáveis por marcar a organização dos assuntos abordados, fazendo a separação entre as seções. Quando um programa é composto por várias delas, como é comum acontecer em revistas eletrônicas como Vídeo Show e Fantástico (Rede Globo) e Tudo a Ver (Rede Record), cada uma dessas seções tem uma vinheta própria, utilizada não só para apresentar o conteúdo que virá mas também para indicar que houve uma mudança de assunto e, assim, não confundir o telespectador. Desse modo, a vinheta aparece estrategicamente, marcando o fluir do tempo, já que a serialidade é uma das principais características da televi- 
são analógica e, portanto, componente formador de sua identidade.

Feitas essas considerações sobre os intervalos de programa é preciso abordar a estrutura do intervalo entre programas. A consideração é breve. Basta perceber que neles prevalecem os comerciais dos tipos autorreferencial e institucional, bem como as vinhetas institucionais. Com isso, a porcentagem de propaganda institucional ou autorreferencial no intervalo como um todo atinge os seguintes números: $39 \%$ na Record; 47\% no SBT; 58\% na Globo; 60\% na Bandeirantes; e $82 \%$ na TV Cultura.

\section{A vinheta do pergaminho, a vinheta do vídeo}

No início do artigo falou-se que a vinheta era um produto característico do meio tipográfico. Como houve uma transposição desse recurso para outras mídias, incluindo a televisão, esta última parte busca comparar o uso original ao uso contemporâneo e estabelecer as características específicas da vinheta televisiva.

Tabela 2. Vinhetas televisivas

\begin{tabular}{l} 
Características originais \\
\hline Caráter simbólico, de cunho sagrado. \\
Utilizada para fins ornamentais. \\
Preenchia espaços vazios da página e \\
chamava a atenção para o texto que \\
adornava, sendo, portanto, sempre um \\
acréscimo a uma forma pronta
\end{tabular}

\begin{tabular}{l} 
Feita por monges \\
Modo de produção artesanal \\
\hline Status de cópia
\end{tabular}

Relação indireta com o texto

\section{Características contemporâneas}

Todas as características se mantêm, exceto o cunho sagrado da produção artística, já que a vinheta contemporânea ilustra textos diversos

Produzida por designers

Linguagem sintética

Status de criação

Relação indireta e direta

Conforme elencado, a vinheta televisiva conserva as características originais da vinheta tipográfica, exceto a qualidade de “sagrada”, já que não está mais ligada a funções religiosas. Dessas primeiras características, é preciso destacar a utilização da vinheta como ornamento e sua aparição como um acréscimo a uma forma estabelecida ou pronta, pois nessas duas características reside o que se pode chamar de "essência" da vinheta. Apesar das carac- 
terísticas particulares da produção e da utilização desse recurso expressivo em diferentes épocas e meios de comunicação, essas duas características (e é preciso que as funções de ornamento e acréscimo estejam juntas) são fundamentais para saber se uma determinada produção gráfica, radiofônica, cinematográfica ou televisiva é uma vinheta de fato.

Cumpridas essas exigências, que outras funções e características específicas imprimiu a televisão a esse produto artístico? São elas: 1) função mercadológica; 2) organização do tempo e dos conteúdos; 3) linguagem videográfica; e 4) possibilidade de relação direta com a forma pronta.

A primeira característica destacada é a função mercadológica da vinheta na televisão, quer dizer, a apresentação e o estabelecimento de marcas. A identificação da emissora e dos programas veiculados ocorre desde o início da televisão brasileira, atendendo necessidades básicas do próprio meio, e permanece até hoje. É verdade que a função de identificação já aparecia nas vinhetas do rádio, mas na televisão essa função foi se aprimorando a ponto de não só apresentar marcas, serviços e produtos, mas desenvolver estratégias para o estabelecimento de contratos com o telespectador. Essa função mercadológica exercida pela vinheta garante também a estética da repetição, já que as marcas em questão são as da emissora ou dos programas por ela veiculados.

Em seguida, tem-se o uso da vinheta na organização dos assuntos, operacionalizando o fluir do tempo televisivo. Essa característica também apareceu logo no início da televisão brasileira. A diferença é que nos primórdios da TV as dificuldades de produção muitas vezes obrigavam as vinhetas a administrar intervalos longos e vazios (sem conteúdo), motivo pelo qual permaneciam no ar tanto tempo (de 10 a 40 minutos). Hoje, se não há a marcação da vinheta, sobretudo no interior dos próprios programas, corre-se o risco de não perceber quando terminou um assunto e começou outro, devido ao ritmo acelerado das informações. Dessa forma, fica evidente a importância da vinheta na formação dessa característica da televisão analógica, a serialidade, já que ela é utilizada para marcar o início e o fim de seções, blocos e programas.

Outro aspecto que merece destaque é a linguagem na construção das vinhetas. Afinal, para que as funções da vinheta na televisão sejam cumpridas, é necessário que ela se "materialize" de alguma forma. Isso significa pensar as próprias qualidades da linguagem uti- 
lizada. Ora, se as imagens são concebidas primeiro em nossa mente para então tomar corpo por intermédio de algum substrato físico do mundo, torna-se evidente que não se pode dizer ou expressar mais do que a linguagem permite.

Sendo assim, é possível dizer que os limites da vinheta televisiva nos dias de hoje podem ser definidos a partir da linguagem utilizada em sua elaboração. Nesse caso, visualmente, as vinhetas de hoje começam e terminam em computação gráfica. Mas esses limites, pautados no videografismo, não devem ser considerados de modo rígido, porque diferentes linguagens podem se articular no desenvolvimento de uma vinheta. Como a computação gráfica tem sido predominantemente a linguagem utilizada na produção de vinhetas, é possível utilizá-la como referencial de delimitação.

Por fim, tem-se a possibilidade de relação direta com a forma pronta ou estabelecida. Tomando por base as iluminuras da Idade Média, observa-se que as vinhetas se relacionavam indiretamente com o texto, sendo formadas, geralmente, por ramagens, flores e folhas. Já as ilustrações eram mais incrementadas, com imagens diversas - pessoas, objetos, cenários - , chegando a compor verdadeiras narrativas.

As vinhetas da televisão parecem ter tomado para si o papel que antigamente era cumprido pela ilustração. Mas pode-se ir além. As capitulares que faziam parte das iluminuras foram também incorporadas pelas vinhetas. Basta lembrar que muitas delas são feitas a partir de logotipos. Assim, pode-se dizer que a vinheta televisiva abarcou todos os elementos da iluminura, tornando-se sua correspondente atual. 


\section{Bibliografia}

AZNAR, S.C. Vinheta: do pergaminho ao vídeo.

São Paulo: Arte \& Ciência, 1997.

COUCHOT, E. "Da representação à simulação".

In: PARENTE, A. (Org.). Imagem-máquina.

Rio de Janeiro: Editora 34, 1993.

MACHADO, A. Máquina e imaginário. São Paulo:

Editora da Universidade de São Paulo, 2001.

Pré-cinemas e pós-cinemas. Campinas: Papirus, 2005.

SANTOS, J. F. dos. O que é pós-moderno. São Paulo:

Brasiliense, 1994. 